\title{
Death and Modern Science: The Hidden Connections, Profound Implications, and a Question of Hope
}

\author{
Allen D. Allen \\ Retired, Scottsdale, AZ, USA \\ Email: allend.allen@yahoo.com
}

How to cite this paper: Allen, A. D (2017). Death and Modern Science: The Hidden Connections, Profound Implications, and a Question of Hope. Open Journal of Philosophy, 7, 94-103.

https://doi.org/10.4236/ojpp.2017.71006

Received: January 19, 2017

Accepted: February 10, 2017

Published: February 13, 2017

Copyright $\odot 2017$ by author and Scientific Research Publishing Inc. This work is licensed under the Creative Commons Attribution International License (CC BY 4.0).

http://creativecommons.org/licenses/by/4.0/

\begin{abstract}
The purpose of this paper is to provide a few examples of how several branches of science have interesting and even profound implications for our understanding of death. The method will be to analyze some established principles from biology, astrophysics, mathematics and quantum mechanics. There are four results: First, the death and biodegradable bodies of Earth's animals played a significant role in the evolution of the human species. In this ironic sense, we owe our lives to death. Second, unnatural death can be framedependent. A person can be alive and well in his proper reference frame despite having died an unnatural death in an external frame. Third, if the multiverse theory is not valid, then the death of the universe is inevitable and irreversible. This is tantamount to the law of increasing entropy. Fourth, events do not go out of existence with the passage of time. Rather, what is lost to the past is the high probability associated with detecting present events. In other words, the high amplitude of present events washes out detection of past events like the daytime sun washes out the stars. Since the unconscious mind does not detect energetic sensory data, it may be timeless as many have suggested. If so, it need not depend upon high amplitude events, thus giving some credence to paranormal psychology. Moreover, the death of the organic brain in its inertial frame of reference may not be synchronized with the death of the unconscious, thus admitting to something like an afterlife. In conclusion, scientists should conduct further research as a follow-up to this early paper in order to gain a deeper understanding of death, an event that is inevitable for us all and has profound consequences.
\end{abstract}

\section{Keywords}

Afterlife, Cosmology, Evolution, Frame-Dependent

Death, Parapsychology 


\section{Introduction}

Death is an inevitable event for all of us and has profound consequences. Hence, one would expect each and every scientist to have an abiding interest in the subject. Surprisingly, this does not appear to be the case. Of course, biotech and pharmaceutical researchers do work hard to develop treatments intended to postpone death. Moreover, a body of medical researchers has maintained a significant interest in the so-called near-death experience (NDE) (Bates \& Stanley, 1985; Jansen, 1990; Greyson, 1997; Jansen, 1997; Greyson, 2000; Parnia, Waller, Yeates, \& Fenwick, 2001; Lange, Greyson, \& Houran, 2004; Nelson, Mattingly, Lee, \& Schmitt, 2006; Greyson, 2007). In the NDE, patients who have lost cardiac function and breathing but have recovered, report an inspiring and benevolent out-of-body experience. This experience often confirms a belief in heaven or establishes such a belief. The mechanisms of action for the NDE have not been elucidated, although several have been proposed. Otherwise, death is well understood as a medical phenomenon (Bernat, Culver, \& Gert, 1981; Wehner, Wehner, Schieffer, \& Subke, 2000; Greenhouse, Kuzminsky, Martin, \& Merryman, 2006; Lustbader, O’Hara, Wijdicks, MacLean, Tajik, Ying, Berg, \& Goldstein, 2011; Kansal \& Havill, 2012).

In light of this milieu, the literature pretty much leaves the subject of death up to religion. To help correct this oversight, the present paper provides a few examples of how various branches of science have interesting, even profound, implications for a deeper understanding of death. Needless to say, death has an inevitable and highly significant impact on all members of society. This is all the more reason that death should be of interest to academicians. The method used here will be to analyze some established principles from biology, astrophysics, mathematics and quantum mechanics. This should provide a jumping-off point for further scientific research intended to achieve a deeper understanding of death.

\section{Death of Organic Life}

\subsection{Evolution}

During the Cambrian period of the Paleozoic era, there was an explosion of terrestrial life when virtually all the animal phyla first appear in the fossil record (Marshall, 2006). What emerged was a plethora of wondrous and strange genera and species, distinct from the later differentiations, such as reptiles and mammals. Some 250 million years later at the Permian-Triassic boundary, there was an unprecedented mass extinction, the most severe mass extinction in the geologic record (Bowring, Erwin, Jin, Martin, Davidek, \& Wang, 1998; Becker, Poreda, Hunt, Bunch, \& Rampino, 2001). Almost 70\% of the terrestrial vertebrate genera and $85 \%$ of marine species became extinct. This was the only mass extinction that affected insects. It set the stage for reptiles to evolve into the dinosaurs that flourished and dominated the land mass of the Earth for many millions of years. Then, 200 million years later, at the Cretaceous-Paleogene boun- 
dary, a large asteroid impact at Chicxulub, Mexico caused the extinction of the dinosaurs (Axelrod \& Bailey, 1968; Schulte, Alegret, Arenillas, Arz, Barton, Bown, Bralower, Christeson, Claeys, Cockell, Collins Deutsch, Goldin, Goto, Grajales-Nishimura, Grieve, Gulick, Johnson, Kiessling, Koeberl, Kring, MacLeod, Matsui, Melosh, Montanari, Morgan, Neal, Nichols, Norris, Pierazzo, Ravizza, Rebolledo-Vieyra, Reimold, Robin, Salge, Speijer, Sweet, Urrutia-Fucugauchi, Vajda, Whalen, \& Willumsen, 2010). This second extinction event, in turn, paved the way for mammals to flourish and evolve, eventually resulting in the human species.

But what if the bodies of terrestrial animals had not been biodegradable? Then, after the great mass extinction at the Permian-Triassic boundary, the land mass of the Earth would have been strewn with the preserved bodies of the wondrous and strange genera and species that emerged during the Cambrian explosion of life. Although the paucity of atmospheric oxygen at the beginning of this period would have favored reptiles (Dudley, 1998), with ubiquitous meat readily available from the preserved carcasses of dead animals, there would have been less of an advantage for carnivores to evolve into the huge size of the large dinosaurs. As the availability of meat increased with the death of each new dinosaur generation, and as the atmosphere regained oxygen, the small, burrowing mammals might have evolved and flourished sooner only to become extinct along with the dinosaurs at the Cretaceous-Paleogene boundary. If so, then intelligent life might never had evolved. Even if it had, human history would obviously have been much different if there had never been any oil on Earth.

Another issue is what would have become of the oceans if marine life had not been biodegradable. The oceans' important source of protein might have been reduced. Due to the incompleteness of the fossil record, this subject necessarily entails some speculation. However, suffice it to say the following:

- The death and biodegradable bodies of Earth's animals played a significant role in the evolution of the human species.

It seems ironic that, in this sense, we owe our lives to death.

\subsection{Frame-Dependent Death}

In quantum mechanics, unitarity conserves information (Cornwall, Levin, \& Tiktopoulos, 1974, 1975). However, the information can become scrambled such that putting it back together would violate the principle of increasing entropy. The conservation of information was challenged when Hawking demonstrated that quantum mechanics would cause black holes to evaporate via Hawking radiation, thus decoupling the future from the past (Aharonova, Cashera, \& Nussinova, 1987; Susskind, 1997).

As I have shown elsewhere (Allen, 2012), Hawking radiation admits to two equally valid realities: An astronaut may be dead and cremated in the reality of his colleagues but alive and well in his own reality. This requires a black hole and a spacecraft firing powerful engines to keep the spacecraft on orbit just above the event horizon. In the reality of the accelerating spacecraft (only) the surface of 
the black hole is blazing hot due to virtual particles that have become real. If an astronaut jumps out of the spacecraft and falls into the black hole, his colleagues aboard the spacecraft will see him incinerated as he falls through the blazing hot surface. This really happens in the reality of the astronauts on orbit. But once an astronaut jumps out of the spacecraft, he is in freefall and not accelerating. As a result, the surface of the black hole is just empty space in his reality and he falls through unscathed. Although this situation requires a black hole and a spacecraft on nearby orbit, it proves a principle:

- Death can be relative to the observer and may fail to occur in the reference frame of an individual who dies an unnatural death in another reference frame.

\subsection{Summary}

Two conclusions have been reached regarding the death of organic life. First, the death and biodegradable bodies of Earth's animals played a significant role in the evolution of the human species. In this ironic sense, we owe our lives to death. Perhaps society should not view death in entirely negative terms. Second, an individual may be alive and well in his own, proper reference frame despite his unnatural death in another, external reference frame. This is of no practical significance since humans have always lived in the inertial frame of the Earth and will for the foreseeable future. (Leaving the Earth's rest frame means much more than travelling to another planet in the Solar System.) Nonetheless, framedependent death should be of academic interest.

\section{Birth and Death of the Cosmos}

Much has been written about the death of the cosmos, including heat death (Cartwright, 2014) and the "big rip" (Brevik \& Gorbunova, 2005). Here we will start at the beginning by considering an unordered pair of directed integers $(-1$, +1 ), and the binary operator + (addition), both of which are given as our field or universe. If the elements of the pair $(-1,+1)$ are combined through addition, then the result is

$$
(-1)+(+1)=0
$$

In other words, the integers in the pair $(-1,+1)$ are annihilated if they combine through addition. Note that the resulting number zero is not directed, i.e., $-0=+0$. Thus, strictly speaking, zero is not an integer and we can say that "integerness" has been annihilated. An obvious simile from physics is the way an electron $\left(\mathrm{e}^{-}\right)$and a positron $\left(\mathrm{e}^{+}\right)$will annihilate rest mass by converting it into energy when the particles combine. As another simile, Gödel, 1938 proved that the set of all sets is empty. Thus, by collecting all nonempty sets into a set of all sets, we annihilate the nonempty sets by virtue of transforming them into the empty set.

The first of these similes is reversible but only in a universe that is a proper subset of a greater whole. As is well-known, a photon can become an unordered 
pair $\left(\mathrm{e}^{-}, \mathrm{e}^{+}\right)$if, and only if, the photon passes close to an atomic nucleus so as to conserve momentum. In a universe comprised only of $\left(\mathrm{e}^{-}, \mathrm{e}^{+}\right)$, the annihilation of $\left(\mathrm{e}^{-}, \mathrm{e}^{+}\right)$is irreversible because there is no atomic nucleus to conserve momentum.

By its very definition, the set of all sets is not the proper subset of a greater whole. Nor is the second simile reversible. If we try to extract a nonempty set from the empty set we obtain

$$
\phi-S=\phi
$$

where $\phi$ is the empty set and $S$ is any nonempty set.

For purposes of Equation (1), annihilation can only be reversed with a twostep process:

1) $0-1=-1$,

2) $0+1=+1$.

But this presumes another pair $(-1,+1)$ beyond the one given that was annihilated, again presuming a field or universe $\{(-1,+1),+\}$ that is the proper subset of a greater whole. The pattern here is ubiquitous and should be obvious. Indeed, it is akin to the law of increasing entropy:

Theorem: Annihilation can be reversible only in a universe that is a proper subset of a greater whole.

In terms of the second law of thermodynamics, annihilation means that all the material objects being considered wind up at the same temperature (an annihilation of free energy). The question, then, is whether the cosmos is a proper subset of a greater whole, as in multiverse theory (Dewitt \& Graham, 1973; Tegmark, 2004; Car, 2009). If, and only if, this is the case, then:

- The singularity of the big bang could have started off empty of free energy.

- The heat death of the cosmos is not inevitable and, in any case, could be reversible.

Otherwise,

- The singularity of the big bang did not start off empty of free energy.

- The heat death of the cosmos is inevitable and irreversible.

\section{Time in Quantum Mechanics}

It is our human intuition that events come into existence from a stochastic future, have an ephemeral existence in the present, and then go out of existence into the deterministic past. However, as I have shown elsewhere (Allen, 1998a), modern physics paints a different picture. The wave function for an event has a nonzero amplitude everywhere in spacetime (Raymer, 1997; Feynman, Hibbs, \& Styer, Extended by Styer, 2005; Griffiths, 2017). Over a small interval, the amplitude or probability of detection reaches a very high peak. It falls off rapidly and exponentially approaching zero asymptotically with distance from the peak amplitude. What changes in time is where the observer is in relation to the peak amplitude, which is what we mean by the present. In other words, the high amplitude of present events blots out past events the same way that the daytime sun 
blots out the stars. By blocking out data from the present and amplifying data from the past with diffraction effects, past events could be seen (Allen, 1998b). However, due to the magnitude of the speed of electromagnetic radiation in a vacuum, this could only be used to see milliseconds into the past, as if an event had happened slightly further away from the observer in space than it actually did. Nonetheless, the philosophical point is interesting:

- Nothing actually dies in the sense of going out of existence. What is lost to the past is the high probability of detecting an event.

Many students of the mind believe that the unconscious mind is timeless (Bonaparte, 1940; Spence, 1990; Hägglund, 2001; Zeki, 2002; Primas, 2003; Ekstrom, 2004; Schoillberger, 2008). In terms of physics, this belief is credible because the unconscious mind does not detect the peak amplitude of an event's wave function, i.e., the present, because it does not detect energetic, sensory data. This could account for numerous anecdotes involving precognition or extrasensory perception (Wolfle, 1937; Rattet \& Bursik, 2001). Perhaps rejection of such phenomena by the scientific community reflects confirmation bias rather than critical thinking.

\section{A Question of Hope for Society to Ponder and for Further Study by Academicians}

For our species, the most hopeful conclusion might seem to be that death can be frame-dependent. Of course, the peculiarities of a black hole and Hawking radiation were needed to prove the principle. But with the principle proved, one might consider whether the people who die in the reference frame of the Earth might still be alive elsewhere in their own frame, just like the falling astronaut in Section 2.2, a thought experiment that is explained in great detail in Allen, 2012. The problem is that the astronaut eliminated his unnatural cause of death by changing frames. Changing frames can only keep a person alive if his cause of death exists in an external frame and is not due to natural causes such as old age or disease. Such natural deaths occur in a person's proper frame and consequently accompany people wherever they might be.

More hopeful for the relevance of human life is the examination of what time does in quantum mechanics. It means that whatever we do, for good or ill, while not directly detectable in the distant future, is nonetheless written indelibly on the fabric of space and time. How interesting that this is admitted to in Steven Spielberg's 2001 movie A. I. Artificial Intelligence. A related point is that the unconscious mind may not be restricted to the peak amplitude of the wave function, i.e., the present, since the unconscious mind does not detect energetic, sensory data. This is consistent with the belief that the unconscious mind is timeless and gives some credence to parapsychology. It also leads to the Chief Philosophical Question of the present paper:

Chief Philosophical Question: If the unconscious mind is not restricted to the present, is the death of the organic brain at a time determined by its inertial reference frame synchronized with the death of the unconscious mind? 
If the answer is in the negative, then we have something like an afterlife. Unfortunately, the Chief Philosophical Question is akin to Pascal's wager (Cargile, 1966). We can never discover the answer from direct experience if the answer is affirmative.

\section{Conclusion}

In order to demonstrate that several branches of modern science have interesting and profound implications for death, this paper has provided examples from biology, astrophysics, mathematics and quantum mechanics. Given the humble purpose of this early paper, the author hopes his colleagues will conduct follow-up studies so as to arrive at a deeper understanding of death. After all, as noted at the outset, death is the fate that awaits us all and it has the most serious of consequences.

\section{Acknowledgements}

I thank my daughter, Corinne, for helpful discussions and my wife for proofreading. I also thank my home-nursing aide, the mother of a boy named Azrael, appropriately enough, for the care she provided during the writing of this paper. Finally, I thank a reviewer for comments that significantly improved this paper.

\section{References}

Aharonova, Y., Cashera, A., \& Nussinova, S. (1987). The Unitarity Puzzle and Planck Mass Stable Particles. Physics Letters B, 191, 51-55. https://doi.org/10.1016/0370-2693(87)91320-7

Allen, A. D. (1998a). A Novel Use of Very Long Baseline Interferometry to Photograph Past Events for Stellar and Planetary Sciences: Implications for Basic Theory. Physics Essays, 11, 132-136. https://doi.org/10.4006/1.3028751

Allen, A. D. (1998b). Method for Measuring Retarded Light through Very Long Baseline Interferometry and Natural or Artificial Diffraction Effects. U. S. Patent No. 5,847,830.

Allen, A. D. (2012). The Weatherman Who Fell Down a Black Hole: What He Can Teach Us about Reality. Physics Essays, 25, 76-83. https://doi.org/10.4006/0836-1398-25.1.76

Axelrod, D. I., \& Bailey, H. P. (1968). Cretaceous Dinosaur Extinction. Evolution, 22, 595-611. https://doi.org/10.2307/2406883

Bates, B. C., \& Stanley, A. (1985). The Epidemiology and Differential Diagnosis of NearDeath Experience. American Journal of Orthopsychiatry, 55, 542-549.

https://doi.org/10.1111/j.1939-0025.1985.tb02704.x

Becker, L., Poreda, R. J., Hunt, A. G., Bunch, T. E., \& Rampino, M. (2001). Impact Event at the Permian-Triassic Boundary: Evidence from Extraterrestrial Noble Gases in Fullerenes. Science, 291, 1530-1533. https://doi.org/10.1126/science.1057243

Bernat, J. L., Culver, C. M., \& Gert, B. (1981). On the Definition and Criterion of Death. Annals of Internal Medicine, 94, 389-394. https://doi.org/10.7326/0003-4819-94-3-389

Bonaparte, M. (1940). Time and the Unconscious. The International Journal of PsychoAnalysis; London, 21, 427.

Bowring, S. A., Erwin, D. H., Jin, Y. G., Martin, M. W., Davidek, K., \& Wang, W. (1998). $\mathrm{U} / \mathrm{Pb}$ Zircon Geochronology and Tempo of the End-Permian Mass Extinction. Science, 280, 1039-1045. https://doi.org/10.1126/science.280.5366.1039 
Brevik, I., \& Gorbunova, O. (2005). Dark Energy and Viscous Cosmology. General Relativity and Gravitation, 37, 2039-2045. https://doi.org/10.1007/s10714-005-0178-9

Car, B. (2009). Universe or Multiverse? Cambridge: Cambridge University Press.

Cargile, J. (1966). Pascal's Wager. Philosophy, 41, 250-257. https://doi.org/10.1017/S003181910005871X

Cartwright, J. (2014). Zombie Cosmos: Are We Living in a Dead Universe? New Scientist, 221, 32-35. https://doi.org/10.1016/S0262-4079(14)60633-3

Cornwall, J. M., Levin, D. N., \& Tiktopoulos, G. (1974). Derivation of Gauge Invariance from High-Energy Unitarity Bounds on the $S$ Matrix. Physical Review D, 10, 11451167. https://doi.org/10.1103/PhysRevD.10.1145

Cornwall, J. M., Levin, D. N., \& Tiktopoulos, G. (1975). Erratum: Derivation of Gauge Invariance from High-Energy Unitarity Bounds on the $S$ Matrix. Physical Review D, 11, 972. https://doi.org/10.1103/PhysRevD.11.972

Dewitt, B. S., \& Graham, N. (1973). The Many Worlds Interpretation of Quantum Mechanics. Princeton, NJ: Princeton University Press.

Dudley, R. (1998). Atmospheric Oxygen, Giant Paleozoic Insects and the Evolution of Aerial Locomotor Performance. Journal of Experimental Biology, 201, 1043-1050.

Ekstrom, S. R. (2004). The Mind beyond Our Immediate Awareness: Freudian, Jungian, and Cognitive Models of the Unconscious. Analytical Psychology, 49, 657-682. https://doi.org/10.1111/j.0021-8774.2004.00494.x

Feynman, R. P., Hibbs, A. R., \& Styer, D. F. (2005). Quantum Mechanics and Path Integrals. Mineola, NY: Dover Publications.

Gödel, K. (1938). The Consistency of the Axiom of Choice and of the Generalized Continuum-Hypothesis. Proceedings of the National Academy of Sciences of the United States of America, 24, 556-557. https://doi.org/10.1073/pnas.24.12.556

Greenhouse, P. K., Kuzminsky, B., Martin, S. C., \& Merryman, T. (2006). Calling a Condition Help. American Journal of Nursing, 106, 63-66. https://doi.org/10.1097/00000446-200611000-00021

Greyson, B. (1997). The Near-Death Experience as a Focus of Clinical Attention. Journal of Nervous \& Mental Disease, 185, 327-334. https://doi.org/10.1097/00005053-199705000-00007

Greyson, B. (2000). Dissociation in People Who Have Near-Death Experiences: Out of Their Bodies or out of Their Minds? Lancet, 355, 460-463. https://doi.org/10.1016/S0140-6736(99)07305-5

Greyson, B. (2007). Consistency of Near-Death Experience Accounts over Two Decades: Are Reports Embellished over Time? Resuscitation, 73, 407-411. https://doi.org/10.1016/j.resuscitation.2006.10.013

Griffiths, D. J. (2017). Introduction to Quantum Mechanics (2nd ed.). Cambridge: Cambridge University Press.

Hägglund, T.-B. (2001). Timelessness as a Positive and Negative Experience. The Scandinavian Psychoanalytic Review, 24, 83-92. https://doi.org/10.1080/01062301.2001.10592620

Jansen, K. L. R. (1990). Neuroscience and the Near-Death Experience: Roles for the NMSA-PCP Receptor, the Sigma Receptor and the Endopsychosins. Medical Hypotheses, 31, 25-29. https://doi.org/10.1016/0306-9877(90)90048-J

Jansen, K. L. R. (1997). The Ketamine Model of the Near-Death Experience: A Central Role for the N-Methyl-D-Aspartate Receptor. Journal of Near-Death Studies, 16, 5-26. https://doi.org/10.1023/A:1025055109480 
Kansal, A., \& Havill, K. (2012). The Effects of Introduction of New Observation Charts and Calling Criteria on Call Characteristics and Outcome of Hospitalised Patients. Critical Care and Resuscitation, 14, 38-43.

Lange, R., Greyson, B., \& Houran, J. (2004). A Rasch Scaling Validation of a "Core" Near-Death Experience. British Journal of Psychology, 95, 161-177.

https://doi.org/10.1348/000712604773952403

Lustbader, D., O’Hara, D., Wijdicks, E. F. M., MacLean, L., Tajik, W., Ying, A., Berg, E., \& Goldstein, M. (2011). Second Brain Death Examination May Negatively Affect Organ Donation. Neurology, 76, 119-124. https://doi.org/10.1212/WNL.0b013e3182061b0c

Marshall, C. R. (2006). Explaining the Cambrian "Explosion" of Animals. Annual Review of Earth and Planetary Sciences, 34, 355-384. https://doi.org/10.1146/annurev.earth.33.031504.103001

Nelson, K. R., Mattingly, M., Lee, S. A., \& Schmitt, F. A. (2006). Does the Arousal System Contribute to near Death Experience? Neurology, 66, 1003-1009. https://doi.org/10.1212/01.wnl.0000204296.15607.37

Parnia, S., Waller, D. G., Yeates, R., \& Fenwick, P. (2001). A Qualitative and Quantitative Study of the Incidence, Features and Aetiology of Near Death Experiences in Cardiac Arrest Survivors. Resuscitation, 48, 149-156.

https://doi.org/10.1016/S0300-9572(00)00328-2

Primas, H. (2003). Between Mind and Matter. Mind and Matter, 1, 81-119.

Rattet, S. L., \& Bursik, K. (2001). Investigating the Personality Correlates of Paranormal Belief and Precognitive Experience. Personality and Individual Differences, 31, 433 444. https://doi.org/10.1016/S0191-8869(00)00148-3

Raymer, M. G. (1997). Measuring the Quantum Mechanical Wave Function. Contemporary Physics, 38, 343-355. https://doi.org/10.1080/001075197182315

Schoillberger, P. (2008). An Apologia for the Human Mind. Group Analysis, 41, 5-33. https://doi.org/10.1177/0533316408088409

Schulte, P., Alegret, L., Arenillas, I., Arz, J. A., Barton, P. J., Bown, P. R., Bralower, T. J., Christeson, G. L., Claeys, P., Cockell, C. S., Collins G. S., Deutsch, A., Goldin, T. J., Goto, K., Grajales-Nishimura, J. M., Grieve, R. A. F., Gulick, S. P. S., Johnson, K. R., Kiessling, W., Koeberl, C., Kring, D. A., MacLeod, K. G., Matsui, T., Melosh, J., Montanari, A., Morgan, J. V., Neal, C. R., Nichols, D. J., Norris, R. D., Pierazzo, E., Ravizza, G., Rebolledo-Vieyra, M., Reimold, W. U., Robin, E., Salge, T., Speijer, R. P., Sweet, A. R., Urrutia-Fucugauchi, J., Vajda, V., Whalen, M. T., \& Willumsen, P. S. (2010). The Chicxulub Asteroid Impact and Mass Extinction at the Cretaceous-Paleogene Boundary. Science, 327, 1214-1218. https://doi.org/10.1126/science.1177265

Spence, D. P. (1990). Theories of the Mind: Science or Literature? Poetics Today, 11, 329-347. https://doi.org/10.2307/1772620

Susskind, L. (1997). Black Holes and the Information Paradox. Scientific American, 276, 52-57. https://doi.org/10.1038/scientificamerican0497-52

Tegmark, M. (2004). Ch. 21: Parallel Universes. In J. D. Barrow, P. C. W. Davies, \& C. L. Harper (Eds.), Science and Ultimate Reality: Quantum Theory, Cosmology, and Complexity (pp. 459-491). Cambridge: Cambridge University Press. https://doi.org/10.1017/CBO9780511814990.024

Wehner, F., Wehner, H.-D, Schieffer, M. C., \& Subke, J. (2000). Delimitation of the Time of Death by Immunohistochemical Detection of Thyroglobulin. Forensic Science International, 110, 199-206. https://doi.org/10.1016/S0379-0738(00)00177-8

Wolfle, D. L. (1937). Review of Rhine, J. B. Extra-Sensory Perception. The Journal of 
Educational Research, 30, 708-710.

Zeki, S. (2002). Neural Concept Formation \& Art Dante, Michelangelo, Wagner Something, and Indeed the Ultimate Thing, Must Be Left over for the Mind to Do. Journal of Consciousness Studies, 9, 53-76.

Submit or recommend next manuscript to SCIRP and we will provide best service for you:

Accepting pre-submission inquiries through Email, Facebook, LinkedIn, Twitter, etc. A wide selection of journals (inclusive of 9 subjects, more than 200 journals)

Providing 24-hour high-quality service

User-friendly online submission system

Fair and swift peer-review system

Efficient typesetting and proofreading procedure

Display of the result of downloads and visits, as well as the number of cited articles Maximum dissemination of your research work

Submit your manuscript at: http://papersubmission.scirp.org/

Or contact ojpp@scirp.org 